\title{
Essential role of microRNA-650 in the regulation of B-cell CLL/lymphoma 11B gene expression following transplantation: A novel mechanism behind the acute rejection of renal allografts
}

\author{
PENG JIN $^{1}$, HONGXI CHEN ${ }^{2}$, JINLIANG XIE ${ }^{1}$, CHENG ZHOU $^{1}$ and XIANGRONG ZHU ${ }^{1}$ \\ ${ }^{1}$ Centre of Organ Transplantation and ${ }^{2}$ Department of General Surgery, Xiangya Hospital, \\ Central South University, Changsha, Hunan 410008, P.R. China
}

Received March 11, 2017; Accepted October 6, 2017

DOI: $10.3892 / \mathrm{ijmm} .2017 .3194$

\begin{abstract}
Kidney transplantation is an effective final therapeutic procedure for patients with end-stage kidney failure. Although advanced immunosuppressive therapy is administered following transplantation, certain patients still suffer from acute allograft rejection. MicroRNAs (miRs) have a potential diagnostic and therapeutic value for acute renal allograft rejection; however, their underlying mechanism of action is largely unknown. In the present study, an increased level of miR-650 was identified to be associated with the downregulation of B-cell CLL/lymphoma 11B (BCL11B) expression in acute renal allograft rejection. Furthermore, in vitro study using human renal glomerular endothelial cells (HRGECs) transfected with a miR-650 mimic revealed that key characteristics of acute renal allograft rejection were observed, including apoptosis, the release of cytokines and the chemotaxis of macrophages, while the effects were reduced in HRGECs transfected with a miR-650 inhibitor. The existence of a conserved miR-650 binding site on the 3 -untranslated region of BCL11B mRNA was predicted by computational algorithms and confirmed by a luciferase reporter assay. Knockdown of BCL11B with small interfering RNA (siRNA) significantly increased the apoptotic rate and significantly decreased the proliferation ability of HRGECs compared with the negative control group. HRGECs transfected with a combination of BCL11B siRNA and the miR-650 mimic demonstrated a significant increase in the rate of apoptosis compared with the control. These results suggest that the upregulation of miR-650 contributes to the development of acute renal allograft rejection by suppression of BCL11B,
\end{abstract}

Correspondence to: Dr Peng Jin, Centre of Organ Transplantation, Xiangya Hospital, Central South University, 87 Xiangya Road, Changsha, Hunan 410008, P.R. China

E-mail: jinpeng_421@aliyun.com

Key words: acute rejection, microRNA-650, apoptosis, kidney transplantation, B-cell CLL/lymphoma 11B which leads to apoptosis and inflammatory responses. Thus, miR-650 and BCL11B may represent potential therapeutic targets for the prevention of acute renal allograft rejection.

\section{Introduction}

Medical advances in recent years have mlade kidney transplantation one of the most effective treatments for patients with end-stage kidney diseases (1). Optimized surgical techniques and the development of immunosuppressive therapy have resulted in improved long-term outcomes for patients following transplantation (1-3). However, these therapies may be impeded by a variety of different factors, including drug doses, adverse side effects and the unique and dynamic immune status of the individual, which leads to certain patients suffering from acute allograft rejection $(4,5)$. Acute rejection, which is caused by the development of cellular immunity following transplantation, has a strong negative prognostic effect on the chances of allograft survival $(6,7)$. Multiple processes are involved in acute rejection, including innate T-cell mediated rejection and adaptive antibody mediated rejection (8). In addition, the etiology of acute rejection is complicated and involves interactions between renal hemodynamics, inflammatory responses and molecular regulatory factors (9). The specifics of these interactions and the molecular mechanisms by which they occur are largely unknown.

MicroRNAs (miRNAs/miRs) are a class of ubiquitously distributed, endogenous, non-coding single-stranded RNAs (10). They are very short 19-25 nucleotide sequences that regulate gene expression by sequence-specific base pairing with the 3'-untranslated region (UTR) of their mRNA target, causing the degradation or translational repression of the mRNA (11). It has been determined that miRNAs are associated with a variety of cellular processes, including proliferation, differentiation, migration, growth, apoptosis and development (12) The aberrant expression of certain miRNAs is associated with multiple pathological conditions, including heart disease (13), kidney disease (14) and various types of cancer (15). Increasing evidence suggests that miRNAs serve critical roles in the regulation of innate and adaptive immune responses $(16,17)$. In addition, previous studies have reported that miRNA regulation is associated with organ 
transplantation and acute allograft rejection, and that miRNAs may be candidate biomarkers for the diagnosis of acute allograft rejection (18-21). An improved understanding of the multifunctional roles of miRNAs in the pathogenesis of acute rejection is crucial for the development of novel diagnostic tools and therapeutic strategies.

miR-650 has been reported to be upregulated in different types of cancer, including gastric cancer (22), lung adenocarcinoma (23) and hepatocellular carcinoma (24). miR-650 has been revealed to contribute to tumor cell proliferation and apoptosis suppression through interactions with upstream regulatory proteins. Zuo et al (25) determined that miR-650 activity was significantly correlated with the downregulation of the tumor suppressor phosphatidylinositol transfer protein CSR1. It has also been demonstrated that p16INK4a induces the expression of miR-650 in MCF7 cells and that miR-650 may downregulate cyclin dependent kinase 1 (CDK1) by pairing with the CDK1 3'-UTR (26). However, to the best of our knowledge miR-650 has not yet been investigated in acute allograft rejection.

The present study revealed that an increasing level of miR-650 was associated with the downregulation of B-cell CLL/lymphoma 11B (BCL11B) gene expression in acute renal allograft rejection. In vitro study using human renal glomerular endothelial cells (HRGECs) identified key events in acute allograft rejection following transfection with miR-650 mimics, whereas the opposite effects were observed in HRGECs transfected with a miR-650 inhibitor. The existence of a conserved miR-650 binding site on the 3'-UTR of BCL11B mRNA was predicted by computational algorithms and confirmed by a luciferase reporter assay. Furthermore, the knockdown of BCL11B using BCL11B-specific small interfering RNA (siRNA) significantly decreased the apoptosis rate of HRGECs. The results of the present study highlight a potential novel diagnostic marker for acute renal allograft rejection and provide novel therapeutic strategies for its treatment.

\section{Materials and methods}

Patient recruitment and sample collection. Serum samples were collected from 29 recipients of renal transplants who underwent surgery at Xiangya Hospital (Central South University, Changsha, China) between March, 2014 and January, 2016. The serum samples were subsequently divided into two groups as follows: i) Transplantation patients with acute rejection (acute rejection group; $n=19$ ); and ii) transplantation patients with continuous stable kidney function (control group; $n=10)$. The samples collected from patients with acute rejection were obtained within $24 \mathrm{~h}$ of their admission to hospital, the serum creatinine level was measured and they were subsequently confirmed as suffering from acute allograft rejection. Interpretation of the biopsy results was performed according to the Updated Banff 07 criteria by a qualified physician (27). All tissue samples were obtained from anonymized excess tissue, which was not required for diagnostic or clinical purposes. The present study was approved by the Ethics Committee of Xiangya Hospital of Central South University. Written informed consent was obtained from all participants. The demographic and clinical characteristics of all patients included in the present study are detailed in Table I.
Hematoxylin and eosin $(H \& E)$ staining. Histological sections (5- $\mu \mathrm{m}$-thick) were perfused with $4 \%$ paraformaldehyde at $4^{\circ} \mathrm{C}$ for $6 \mathrm{~h}$ and stained with H\&E (Sigma-Aldrich; Thermo Fisher Scientific, Inc., Waltham, MA, USA) for $5 \mathrm{~min}$ at room temperature. The results were observed under an inverted microscope (IX81; Olympus Corp., Tokyo, Japan) at a magnification of $\times 20$.

Immunohistochemistry. The sections were embedded in paraffin and sectioned (5- $\mu \mathrm{m}$-thick). Subsequently, the sections were perfused with $4 \%$ paraformaldehyde at $4^{\circ} \mathrm{C}$ for $6 \mathrm{~h}$, then placed onto Poly-Prep Slides (Sigma-Aldrich; Thermo Fisher Scientific, Inc.) and dried at $60^{\circ} \mathrm{C}$ for $1 \mathrm{~h}$. The sections were deparaffinized in xylene (three times, $5 \mathrm{~min}$ each) at room temperature and hydrated in $100 \%$ ethanol followed by $95 \%$ ethanol. Then, the sections were treated with sodium citrate $(10 \mathrm{mM})$ at $95^{\circ} \mathrm{C}$ for $10 \mathrm{~min}$ and placed at room temperature for $30 \mathrm{~min}$. Expression levels were then detected using a Vectastain Universal elite ABC kit (1:50; cat. no. PK-6200; Vector Laboratories, Inc., Burlingame, CA, USA). The sections were blocked with $5 \%$ normal horse serum (Dako; Agilent Technologies, Inc., Santa Clara, CA, USA) for $30 \mathrm{~min}$ at room temperature and incubated with anti-BCL11B antibodies (1:500; cat. no. ab18465; Abcam, Cambridge, UK) at $4^{\circ} \mathrm{C}$ overnight. Next, the sections were incubated with goat antirat IgG H\&L (phycoerythrin) secondary antibodies (1:1,000; cat. no. ab7010; Abcam) for $15 \mathrm{~min}$ at room temperature. Subsequently, the sections were treated with a 3,3'-diaminobenzidine kit (Signet Laboratories, Inc., Dedham, MA, USA). The nuclei were stained with hematoxylin (cat. no. 790-2208; Ventana Medical Systems, Inc., Tucson, AZ, USA). The results were observed under an IX81 inverted microscope (magnification, $\mathrm{x} 20$ ).

Cell culture. HRGECs (cat. no. 4000) were cultured in endothelial cell medium (ECM) (both from ScienCell Research Laboratories, Inc., San Diego, CA, USA) with 10\% fetal bovine serum (FBS; cat. no. SH30071.03; HyClone; GE Healthcare Life Sciences, Logan, UT, USA), 100 U/ml penicillin, $100 \mathrm{mg} / \mathrm{ml}$ streptomycin and $2 \mathrm{mM}$ glutamine (cat. no. 11090-081) (both from Thermo Fisher Scientific, Inc.). The HRGECs were incubated in an atmosphere with $5 \% \mathrm{CO}_{2}$ at $37^{\circ} \mathrm{C}$. Once they reached $70-80 \%$ confluence, the cells were split according to standard procedures. Following the experimental procedures, the cells were harvested in Dulbecco's modified Eagle's medium (cat. no. 08459-35; Nacalai Tesque, Inc., Kyoto, Japan) with $1 \%$ FBS in preparation for biochemical analyses.

Immunofluorescence staining. Cells were fixed with $4 \%$ paraformaldehyde for $10 \mathrm{~min}$ at room temperature, and subsequently blocked with $5 \%$ FBS containing $0.5 \%$ Triton X-100 for $5 \mathrm{~min}$ at room temperature. The HRGECs were then incubated overnight at $4^{\circ} \mathrm{C}$ with primary antibodies directed against BCL11B (1:500; cat. no. ab18465; Abcam) and then with Alexa Fluor ${ }^{\circledR} 488$-conjugated goat anti-rabbit IgG (cat. no. A-11034; Thermo Fisher Scientific, Inc.) for $1 \mathrm{~h}$ at room temperature. Cell slides were mounted with mounting buffer containing DAPI and immunofluorescence was observed under a fluorescence microscope (magnification, $\mathrm{x} 10$ ). 
Table I. Demographic and clinical characteristics of renal allograft recipients.

\begin{tabular}{|c|c|c|}
\hline \multirow[b]{2}{*}{ Characteristic } & \multicolumn{2}{|c|}{ Group } \\
\hline & $\begin{array}{l}\text { No } \\
\text { rejection }\end{array}$ & $\begin{array}{l}\text { Acute } \\
\text { rejection }\end{array}$ \\
\hline No. of patients & 19 & 10 \\
\hline Male, no. (\%) & $12(63)$ & $8(80)$ \\
\hline Female, no. (\%) & $7(37)$ & $2(20)$ \\
\hline Age, year (range) & $41.5(25-65)$ & $38.7(22-54)$ \\
\hline Type of allograft & - & - \\
\hline Deceased donor & 19 & 9 \\
\hline Living donor & 0 & 1 \\
\hline Type of donor & - & - \\
\hline Related & 0 & 1 \\
\hline Unrelated & 19 & 9 \\
\hline Data from ultrasound & - & - \\
\hline Increased interlobar arteries RI & 0 & 7 \\
\hline Normal interlobar arteries RI & 19 & 3 \\
\hline $\begin{array}{l}\text { Urine volume }(\mathrm{ml} / 24 \mathrm{~h}) \text {, } \\
\text { mean } \pm \mathrm{SD}\end{array}$ & $2124.8 \pm 22.2$ & $1790.6 \pm 24.7$ \\
\hline $\begin{array}{l}\text { Blood creatinine level }(\mu \mathrm{mol} / \mathrm{l}) \\
\text { mean } \pm \mathrm{SD}\end{array}$ & $223.6 \pm 16.3$ & $568.2 \pm 20.3$ \\
\hline
\end{tabular}

RI, resistive index; SD, standard deviation.

$R N A$ extraction and reverse transcription-quantitative polymerase chain reaction $(R T-q P C R)$. Total RNA was extracted using TRIzol reagent (cat. no. 15596-026; Invitrogen; Thermo Fisher Scientific, Inc.) from acute rejection and normal allograft tissues, and the transfected HRGECs, according to the manufacturer's protocol. First-strand cDNA was synthesized from $1 \mu \mathrm{g}$ of total RNA using the RevertAid First Strand cDNA Synthesis kit (Thermo Fisher Scientific, Inc.) according to the manufacturer's protocol. qPCR was then performed with the KAPA SYBR FAST qPCR kit (cat. no. KK4601; Kapa Biosystems, Inc., Wilmington, MA, USA) on a real-time PCR system. The reaction was performed in a $20 \mu \mathrm{l}$ volume and the thermocycling conditions were as follows: $95^{\circ} \mathrm{C}$ for $10 \mathrm{~min}$; 38 cycles of $95^{\circ} \mathrm{C}$ for $10 \mathrm{sec}, 60^{\circ} \mathrm{C}$ for $2 \mathrm{~min}$ and $72^{\circ} \mathrm{C}$ for $2 \mathrm{~min}$; and then $72^{\circ} \mathrm{C}$ for $10 \mathrm{~min}$. Each assay was performed in triplicate and $\beta$-actin or U6 was used as the endogenous control gene. The primer sequences used were as follows: BCL11B forward, 5'-TGCCAGTGTCAGTTGTCAGG-3' and reverse, 5'-CCAGGT AGATGCGGAAGC-3'; miR-650 forward, 5'-ACACTCCAGC TGGGAGGAGGCAGCGCTCT-3' and reverse, 5'-CTCAACT GGTGTCGTGGAGTCGGCAATTCAGTTGAGGTCCTG-3'; U6 forward, 5'-CTCGCTTCGGCAGCACA-3' and reverse, 5'-AACGCTTCACGAATTTGCGT-3'; and $\beta$-actin forward, 5'-ATCGTGCGTGACATTAAGGAGAAG-3' and reverse, 5'-AGGAAGGAAGGCTGGAAGAGTG-3'. The relative amount of miR-650 and BCL11B was calculated using the $2^{-\Delta \Delta C q}$ method with U6 and $\beta$-actin as the controls, respectively (28).
miR-650 mimic, inhibitor and mock transfection. An miR-650 mimic, inhibitor and mock (scrambled control) were chemically synthesized by Shanghai GenePharma Co., Ltd. (Shanghai, China). The sequences for the miR-650 mimic, inhibitor and mock were 5'-AGGAGGCAGCGCUCUCAGGAC-3', 5'-GUC CUGAGAGCGCUGCCUCCU-3' and 5'-UUCUCCGAACGU GUCACGUTT-3', respectively. Cells $\left(5 \times 10^{4}\right.$ cells/well) were seeded in 6-well plates in ECM without antibiotics. The miR-650 mimic, inhibitor and mock $(50 \mathrm{nM})$ were transfected into HRGECs at $80 \%$ confluence using Lipofectamine ${ }^{\mathrm{TM}} 3000$ reagent (Invitrogen; Thermo Fisher Scientific, Inc.) according to the manufacturer's protocol.

siRNA transfection. The BCL11B-specific siRNA and a nonsilencing negative control (NC) siRNA were chemically synthesized by Shanghai GenePharma Co., Ltd. The BCL11B targeting sequence was 5'-CCUGGAGAAACACAUGAA ATT-3' (sense). The sequence of the control siRNA was 5'-UUCUCCGAACGUGUCACGUTT-3' (sense). HRGECs $\left(2 \times 10^{4}\right.$ cells/well) were transfected with BCL11B-sepcific siRNA $(50 \mu \mathrm{M})$ or NC siRNA $(50 \mu \mathrm{M})$ using Lipofectamine 3000 reagent for $24 \mathrm{~h}$ according to the manufacturer's protocols.

Determination of cell proliferation using the cell counting kit-8 (CCK-8) assay. The proliferation assay was performed using a CCK-8 assay (cat. no. CK04; Dojindo Molecular Technologies, Inc., Shanghai, China) according to the manufacturer's protocol to evaluate cell proliferation. Cells were seeded at a density of $5 \times 10^{4}$ cells/well in a 96 -well plate. At each time point $(0,24,48$ and 72 h) CCK-8 solution $(15 \mu \mathrm{l})$ was added to each well, and the cells were further incubated for $2 \mathrm{~h}$ at $37^{\circ} \mathrm{C}$. The absorbance of samples at $450 \mathrm{~nm}$ was then determined using a microplate plate reader.

Determination of apoptosis by flow cytometry. The rate of cell apoptosis was determined using an Annexin V-fluorescein isothiocyanate (FITC)/propidium iodide (PI) apoptosis detection kit (BioVision, Inc., Milpitas, CA, USA). HRGECs were detached with trypsin-EDTA and washed with phosphatebuffered saline (PBS). They were subsequently resuspended in a binding buffer [10 mM HEPES ( $\mathrm{pH} 7.4) ; 150 \mathrm{mM}$ $\mathrm{NaCl} ; 5 \mathrm{mM} \mathrm{KCl} ; 1 \mathrm{mM} \mathrm{MgCl} ; 1.8 \mathrm{mM} \mathrm{CaCl}_{2}$ ] containing Annexin V-FITC $(1 \mathrm{~g} / \mathrm{ml})$ and further incubated for $20 \mathrm{~min}$ at the room temperature. At $10 \mathrm{~min}$ prior to the end of incubation, PI (10 g/ml) was added to the cell suspension to stain necrotic cells. The cells were then analyzed via fluorescenceactivated cell sorting using a FACSCalibur flow cytometer (BD Biosciences, San Jose, CA, USA) equipped with a $488 \mathrm{~nm}$ excitation laser, and analyzed using ModFit LT 2.0 software (Verity Software House, Topsham, ME, USA).

Cell cycle analysis using flow cytometry. Cells were harvested and washed with cold PBS, and subsequently fixed with $70 \%$ ethanol overnight at $-20^{\circ} \mathrm{C}$. The fixed cells were then washed with cold PBS, centrifuged $(1,000 \mathrm{x}$ g for $10 \mathrm{~min}$ at $4^{\circ} \mathrm{C}$ ) and the supernatant was discarded. The cells were stained with a PI solution $(10 \mu \mathrm{g} / \mathrm{ml}$ RNase A; $50 \mu \mathrm{g} / \mathrm{ml}$ PI $)$ at $37^{\circ} \mathrm{C}$ for $30 \mathrm{~min}$ in the dark. The cell cycle distribution was then analyzed using a flow cytometer with CellQuest 3.0 software (BD Biosciences). 
Cytokine and chemokine enzyme-linked immunosorbent assay (ELISA). The quantification of cytokines and chemokines were evaluated using ELISA kits, as described below (eBioscience; Thermo Fisher Scientific, Inc.). The levels of pro-inflammatory cytokines and chemokines were analyzed $48 \mathrm{~h}$ post-transfection. The homogenates were sonicated for $20 \mathrm{sec}$ at $400 \mathrm{~W}$ at $4^{\circ} \mathrm{C}$ and centrifuged at $13,000 \mathrm{x} \mathrm{g}$ for $10 \mathrm{~min}$ at $4^{\circ} \mathrm{C}$. The total protein concentration was measured using a $\mathrm{DC}^{\mathrm{TM}}$ protein assay (Bio-Rad Laboratories, Inc., Hercules, CA, USA) prior to quantification of interleukin-2 (IL-2) (cat. no. BMS221-2), IL-9 (cat. no. 88-7958-88), IL-13 (cat. no. 88-7439-88), interferon- $\gamma($ IFN- $\gamma)$ (cat. no. KHC3014) and chemokine (C-C motif) ligand 5 (cat. no. BMS287-2INST) by ELISA according to the manufacturer's protocol. Data was expressed as $\mathrm{pg} / \mathrm{mg}$ of total protein.

Macrophage chemotactic assay. A macrophage chemotactic assay was performed using Transwell cell migration chambers with $5 \mu \mathrm{m}$-pore inserts (Cell Biolabs, Inc., San Diego, CA, USA) in a 24-well plate. The lower chambers contained ECM that the HRGECs were cultured in for $48 \mathrm{~h}$ after transfection with the miR-650 mimic, inhibitor or mock as a chemotactic stimulus. A total of $3 \times 10^{5}$ (10,000 cells/insert) THP-1 macrophages (cat. no. AA-CELL-63; American Type Culture Collection, Manassas, VA, USA) were placed into the upper chambers in a serum-free RPMI-1640 (cat. no. 430-1800EG; Gibco; Thermo Fisher Scientific, Inc.). The percentage of cells that migrated to the lower chamber was determined by Invitrogen CyQuant ${ }^{\mathrm{TM}}$ GR (Thermo Fisher Scientific, Inc.) staining for $20 \mathrm{~min}$ at $37^{\circ} \mathrm{C}$. Fluorescence was measured with a Victor 1420 Multilabel Counter microplate reader (Wallac, Turku, Finland) at 480 and $520 \mathrm{~nm}$, and analyzed by ImageJ (version 1.45s; National Institutes of Health, Bethesda, MD, USA) and 3D Slicer (version 4.3; slicer.org) software.

Western blot analysis. For western blot analysis, acute rejection and normal allograft samples were sonicated for $5 \mathrm{sec}$ on ice twice at $100 \mathrm{~W}$ in $50 \mathrm{mM}$ lysis buffer [3.1 mM sucrose ( $\mathrm{pH} 7.4)$; $1 \mathrm{mM}$ dithiothreitol, $10 \mu \mathrm{g} / \mathrm{ml}$ leupeptin; $10 \mu \mathrm{g} / \mathrm{ml}$ soybean trypsin inhibitor; $2 \mu \mathrm{g} / \mathrm{ml}$ aprotinin; $0.1 \%$ Triton $\mathrm{X}-100]$. Homogenates were centrifuged at $10,000 \times \mathrm{g}$ at $4^{\circ} \mathrm{C}$ for $20 \mathrm{~min}$ and the supernatants were collected. The total protein concentration was measured using the Bradford protein assay (Bio-Rad Laboratories, Inc.). Protein lysates (30 $\mu \mathrm{g} /$ lane) were separated using $10 \%$ sodium dodecyl sulfate-polyacrylamide gel electrophoresis (SDS-PAGE) and transferred to polyvinylidene difluoride membranes. Following blocking with $1 \%$ bovine serum albumin (BSA; cat. no. EQBAH62; Europa Bioproducts, Ltd., Cambridge, UK) for $1.5 \mathrm{~h}$ at room temperature, the membranes were incubated overnight with monoclonal primary antibodies directed against caspase- 8 (cat. no. ab32397; Abcam) and BCL11B (cat. no. ab28448) [both Abcam and diluted 1:1,000 in PBS-Tween-20 (PBS-T) with $1 \% \mathrm{BSA}$ ] at $4^{\circ} \mathrm{C}$ overnight. The membranes were then washed in PBS-T three times (10 $\mathrm{min} /$ wash $)$ and probed with the appropriate secondary antibody (1:2,000; cat. no. ab6721; Abcam) for $1 \mathrm{~h}$ at room temperature. The membranes were developed using enhanced chemiluminescence (Immun-Star HRP Chemiluminescent kit; Bio-Rad Laboratories, Inc.), and the band densities were measured with a Versa Doc ${ }^{\mathrm{TM}}$ MP 5000 molecular imager and Quantity One software (version 4.6) (both Bio-Rad Laboratories, Inc.). Equal protein loading was verified by measurement of the glyceraldehyde 3-phosphate dehydrogenase (GAPDH) level with a mouse monoclonal antibody (1:2,000; cat. no. ab8245; Abcam).

miR-650 target prediction and verification by luciferase assay. The putative targets of miR-650 were predicted using TargetScan (version 6.2; targetscan.org), miRBase (version 21; miRBase.org), PicTar (version 4.0.24; pictar.mdcberlin.de) and miRanda (version 3.3a; microrna.org). The human BCL11B wild-type and mutant 3 '-UTR reporter vectors were constructed by inserting annealed oligonucleotides with flanking restriction sites into a pmirGLO Dual-Luciferase miRNA Target Expression Vector (Promega Corp., Madison, WI, USA). A total of $3 \times 10^{5}$ cells were seeded in a 24 -well plate and co-transfected with the wild-type or mutant BCL11B vectors and the miR-650 mimic using Lipofectamine 3000 (Thermo Fisher Scientific, Inc.). Firefly luciferase and Renilla luciferase signals were measured after $48 \mathrm{~h}$ using the Dual-luciferase assay reporter kit (cat. no. E1910; Promega Corp.) and quantified using a Lumat LB 9501 luminator. A Renilla plasmid was used as an internal reference and Firefly luciferase activity was normalized to Renilla luciferase.

Statistical analysis. Statistical calculations were performed using GraphPad Prism software (version 6; GraphPad Software, Inc., La Jolla, CA, USA). Data are presented as the mean \pm standard error of the mean. A Student's t-test was used for comparisons between two groups and multiple-factor analysis was used was used for the comparisons of multiple groups. $\mathrm{P}<0.05$ was considered to indicate a statistically significant difference.

\section{Results}

miR-650 expression is increased and BCL11B expression is decreased in acute kidney rejection. The expression of miR-650 has been evaluated in different types of cancer (29); however, to the best of our knowledge, it has not yet been investigated in acute allograft rejection after kidney transplantation. The level of miR-650 expression in the acute rejection group compared with the control group was determined using RT-qPCR. Significant upregulation of miR-650 was identified in the acute rejection group in comparison with the control group (Fig. 1A). The protein expression of BCL11B was evaluated by western blot analysis. This indicated that BCL11B expression was notably lower in the acute rejection group compared with the control group (Fig. 1B). RT-qPCR reported similar results in regards to BCL11B mRNA expression, which was significantly lower in the acute rejection group compared with the control group (Fig. 1A).

Histological features of acute rejection. Histological sections from the patients were stained with $\mathrm{H} \& \mathrm{E}$ in order to determine the main histologic features in the acute rejection group compared with the control group (Fig. 1C). These included margination of neutrophils in peritubular capillaries, arterial fibrinoid necrosis, thrombotic microangiopathy and acute tubular injury. Furthermore, immunohistochemistry analysis revealed that BCL11B expression was markedly 

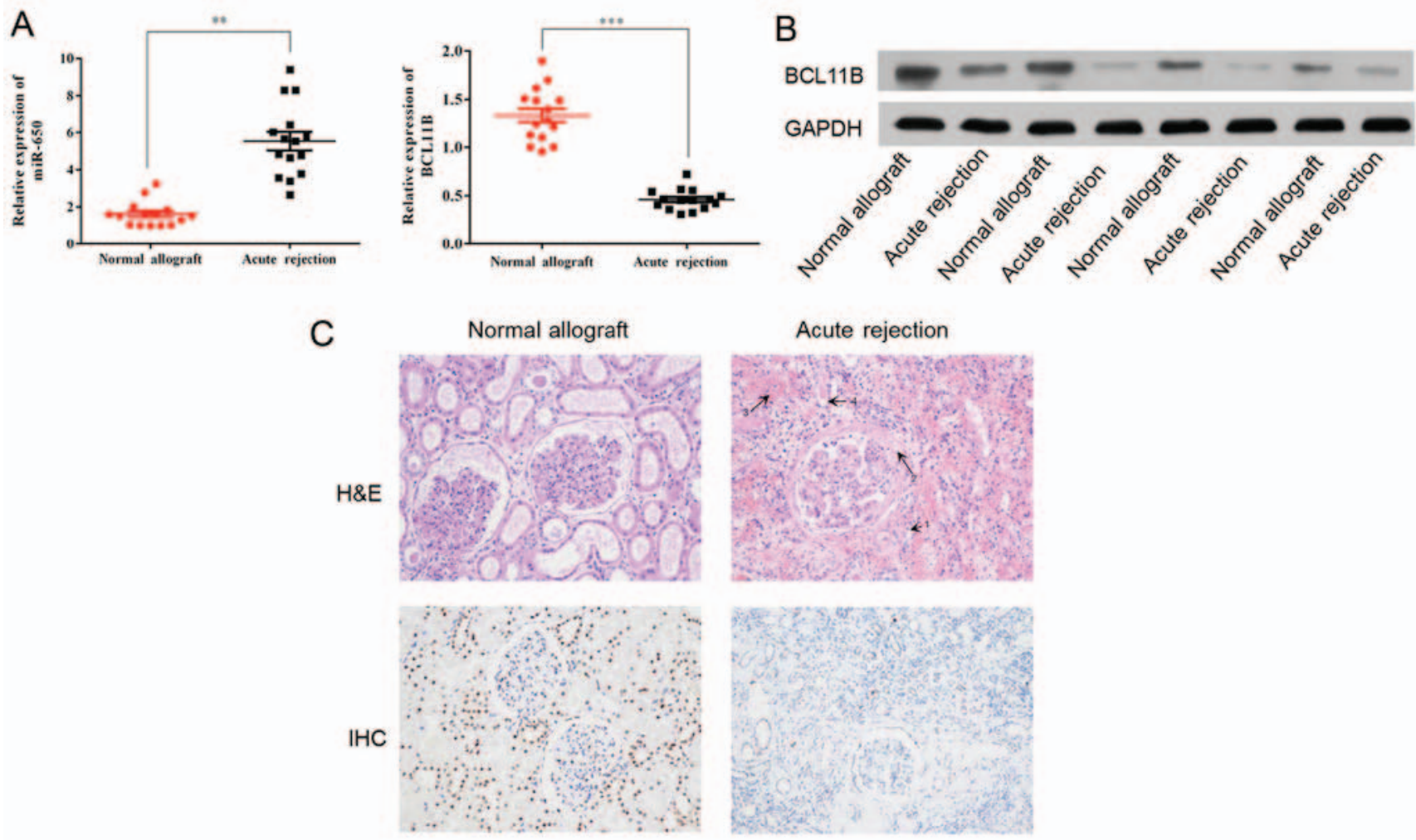

Figure 1. Changes in the acute rejection group compared with the control group. (A) The relative expression levels of miR-650 and BCL11B RNA in the acute rejection and normal allograft groups were measured by reverse transcription-quantitative polymerase chain reaction analysis. (B) Western blot analysis was performed to measure BCL11B protein expression. (C) Histological images of the acute rejection group were determined by H\&E staining (magnification, $\mathrm{x} 20)$. The black arrows indicate the margination of neutrophils in peritubular capillaries, arterial fibrinoid necrosis, thrombotic microangiopathy and acute tubular injury. The BCL11B level was analyzed by IHC. " P<0.05. BCL11B, B-cell CLL/lymphoma 11B; miR, microRNA; H\&E, hematoxylin and eosin; IHC, immunohistochemistry.

A

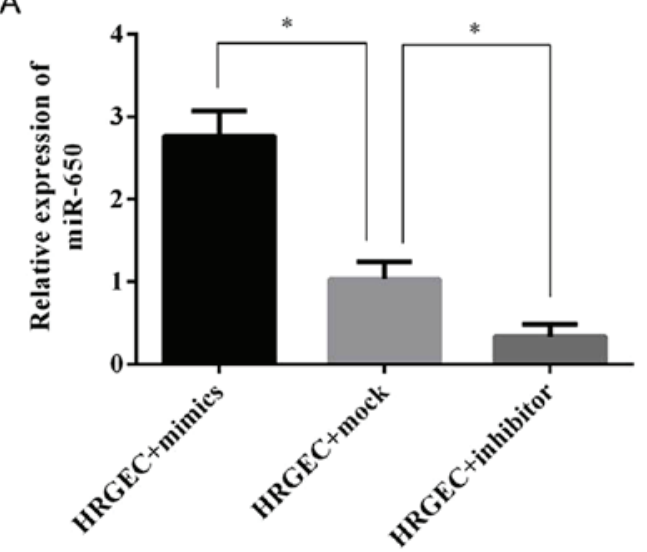

B $\rightarrow$ HRGEC+mimics

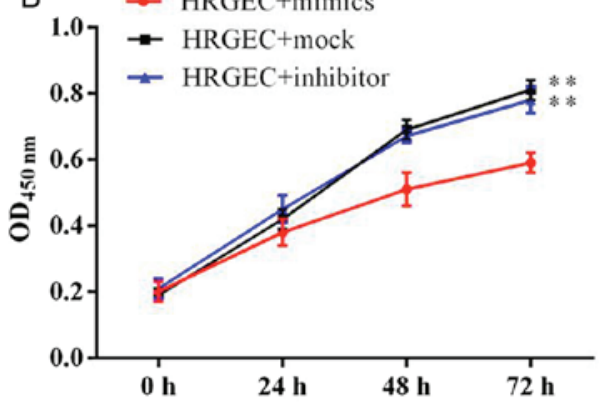

Figure 2. Transfection of the miR-650 mimic, mock or inhibitor into HRGECs. (A) The relative expression level of miR-650 was measured by reverse transcription-quantitative polymerase chain reaction analysis following transfection. The relative expression is given as the mean of four independent experiments. ${ }^{*} \mathrm{P}<0.05$. (B) A cell counting kit- 8 assay was performed at 24,48 and $72 \mathrm{~h}$ to measure HRGEC viability following transfections. ${ }^{* *} \mathrm{P}<0.01$ vs. the mimic group. HRGEC, human renal glomerular endothelial cell; miR, microRNA; OD, optical density.

increased in the acute rejection group in comparison with the control (Fig. 1C).

Transfection of the miR-650 inhibitor and mimic into $H R G E C s$. To explore the functional role of miR-650 in acute renal rejection, an miR-650 mimic, inhibitor or mock were transfected into HRGECs. The expression level of miR-650 was then evaluated using RT-qPCR (Fig. 2A). It was revealed that the miR-650 mimic significantly increased the level of miR-650, whereas the miR-650 inhibitor significantly decreased the level of endogenous miR-650, in comparison with cells transfected with the miR-650 mock.

Upregulation of miR-650 significantly decreases HRGEC viability and increases apoptosis. The effect of miR-650 on cell viability and proliferation were determined. The CCK-8 

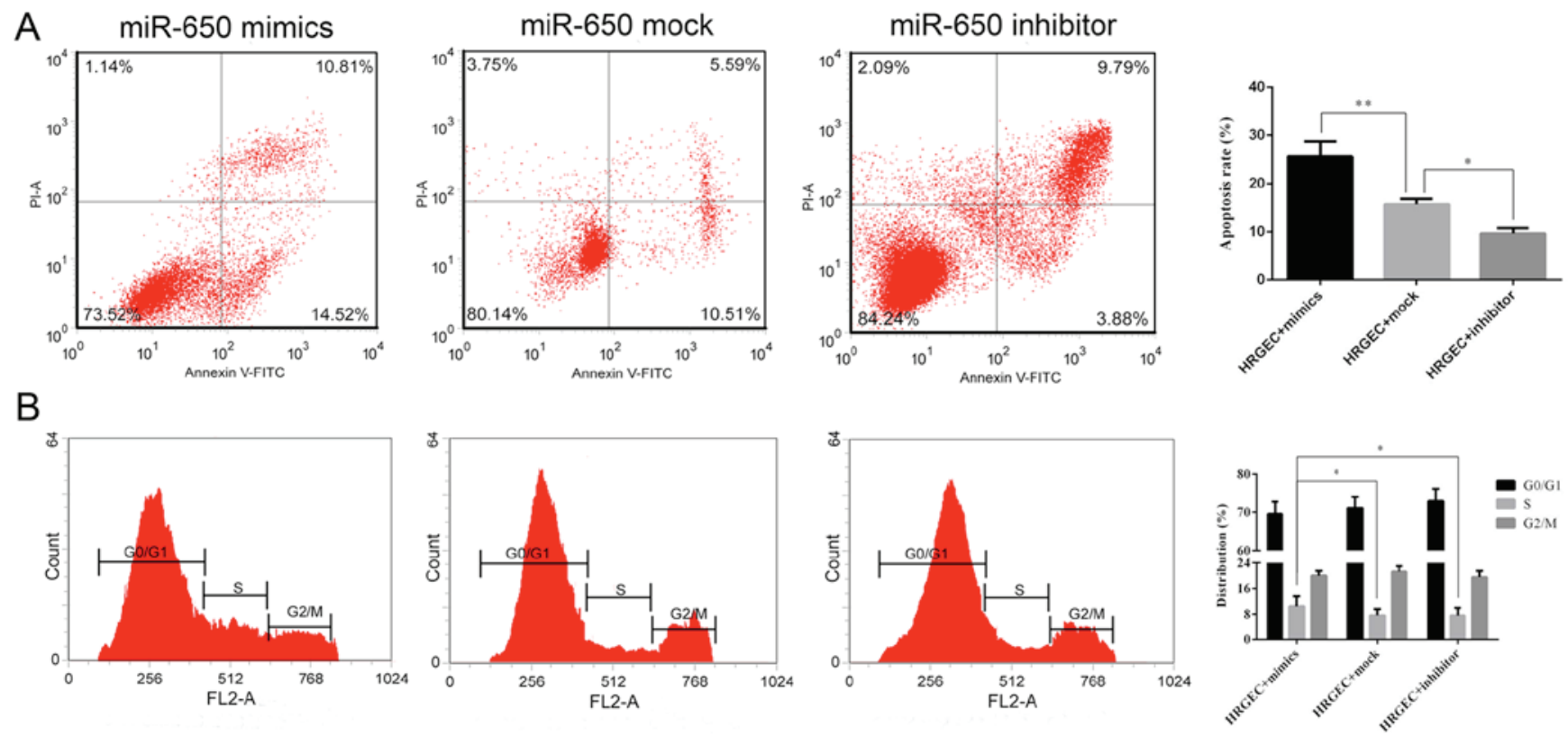

Figure 3. Apoptotic rate and cell cycle analysis of HRGECs following transfection of the miR-650 mimic, mock or inhibitor. (A) The apoptotic rate of each group was detected by Annexin V-FITC/PI staining and flow cytometry. In the flow charts the lower right quadrant indicates early apoptotic cells, and the upper right quadrant indicates necrotic and late apoptotic cells. (B) Cell cycle analysis of the HRGECs was performed using PI and flow cytometry. ${ }^{*} \mathrm{P}<0.05$ and ${ }^{* *} \mathrm{P}<0.01$. HRGEC, human renal glomerular endothelial cell; miR, microRNA; FITC, fluorescein isothiocyanate; PI, propidium iodide.

A
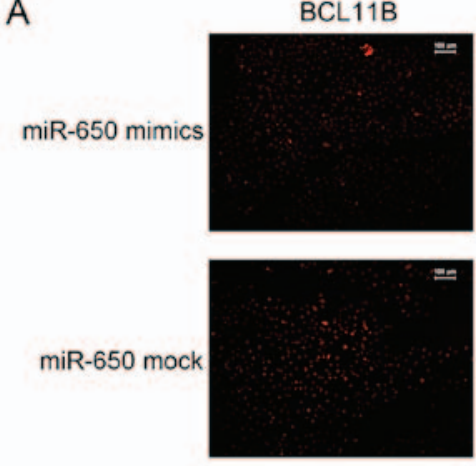

miR-650 inhibitor
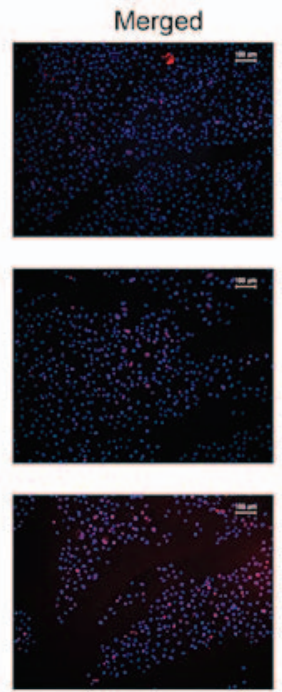

DAPI
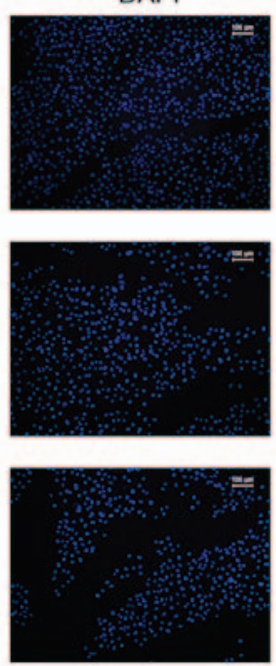

B

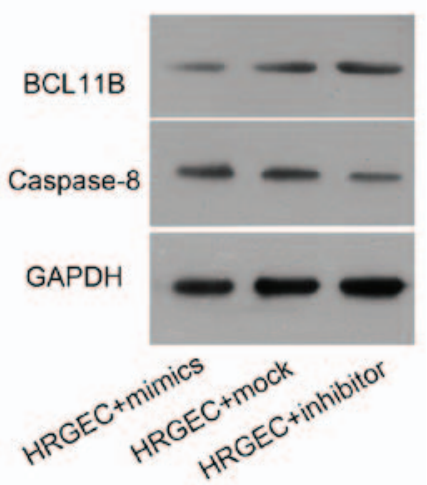

Figure 4. Expression of BCL11B in HRGECs transfected with the miR-650 mimic, mock or inhibitor. (A) The expression of BCL11B was determined by immunofluorescence analysis. (B) Western blot analysis was performed to measure the protein expression of caspase-8 and BCL11B. BCL11B, B-cell CLL/lymphoma 11B; HRGEC, human renal glomerular endothelial cell; miR, microRNA.

assay demonstrated that $48 \mathrm{~h}$ after transfection with the miR-650 mimic cell viability was significantly decreased compared with cells transfected with the miR-360 inhibitor or mock (Fig. 2B).

The rate of apoptosis was determined by flow cytometry. The cell apoptosis rate was significantly increased in cells transfected with miR-650 mimics compared with the cells transfected with the miR-650 mock (Fig. 3A). Additionally, the cells transfected with the miR-650 inhibitor had a significantly lower apoptosis rate compared with the mock group (Fig. 3A). Cell cycle distribution was measured by flow cytometry, and it was revealed that the proportion of cells in $\mathrm{S}$ phase was significantly increased in the miR-650 mimic group compared with the mock and inhibitor groups, indicating that miR-650 inhibited $G_{1}$ and $G_{2} / M$ phase arrest to promote cell proliferation (Fig. 3B).

Immunofluorescence analysis revealed that the level of BCL11B was notably reduced in cells transfected with the miR-650 mimic, whereas it was notably increased in cells transfected with the miR-650 inhibitor (Fig. 4A). Western blot analysis demonstrated that the BCL11B protein expression was markedly higher in cells transfected with the miR-650 inhibitor compared with cells transfected with the miR-650 mimic (Fig. 4B). By contrast, the expression of caspase- 8 was 


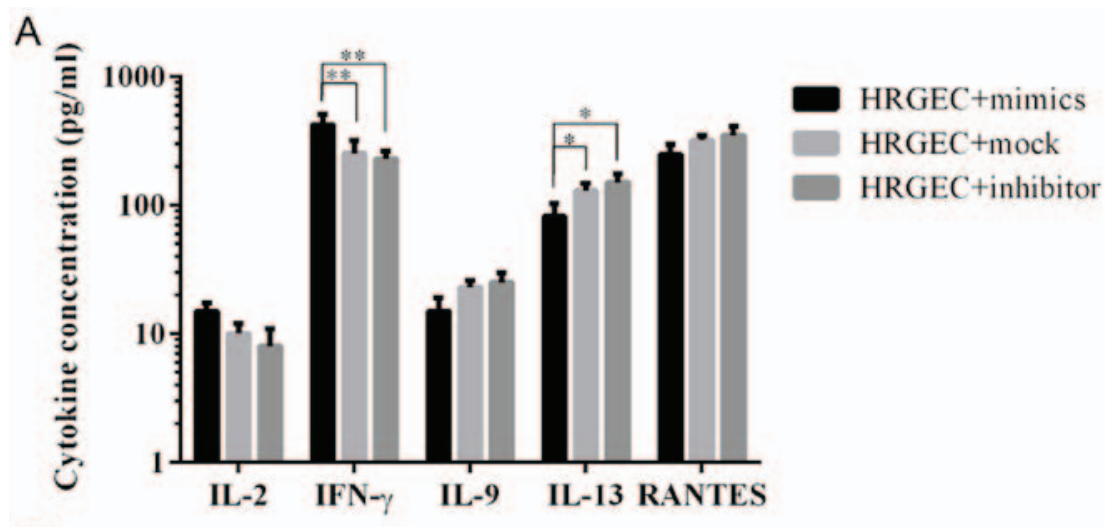

B

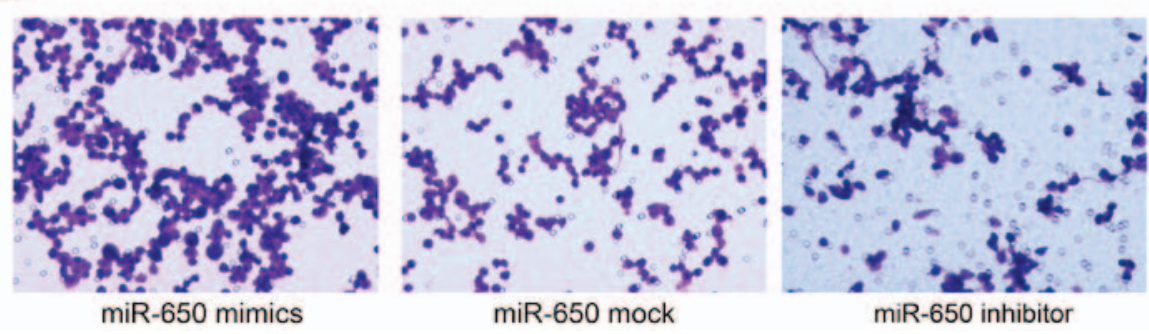

Figure 5. miR-650 affects the release of allograft rejection-associated cytokines from HRGECs and regulates macrophage chemotaxis. (A) Levels of proinflammatory cytokines and chemokines were measured by ELISA following the transfection of the miR-650 mimic, mock or inhibitor. (B) A chemotaxis assay was performed to evaluate macrophage chemotaxis towards a conditioned medium from cells transfected with the miR-650 mimic, mock or inhibitor (magnification, $\mathrm{x} 20$ ). ${ }^{*} \mathrm{P}<0.05$ and ${ }^{* *} \mathrm{P}<0.01$. miR, microRNA; HRGEC, human renal glomerular endothelial cell; IL, interleukin; IFN, interferon; RANTES, chemokine (C-C motif) ligand 5; ELISA, enzyme-linked immunosorbent assay.

\section{A 3' CAGGACUCUCGCGACGGAGGA 5' has-miR-650 5'... GCUGACCUGACUUGCCUCCG...3' BCL11B-WT}

B

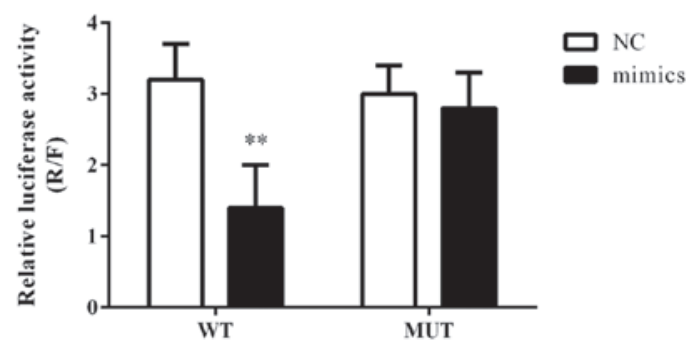

Figure 6. BCL11B as a target of miR-650. (A) The conserved miR-650 binding site of the 3'-untranslated region of BCL11B mRNA was predicted using software packages. (B) A luciferase activity assay was performed on the lysates of human renal glomerular endothelial cells transfected with plasmids encoding WT or MUT BCL11B in the presence of miR-650 or a NC. ${ }^{* *} \mathrm{P}<0.01$ vs. the NC group. BCL11B, B-cell CLL/lymphoma 11B; miR, microRNA; WT, wild-type; NC, negative control; MUT, mutated.

enhanced in cells transfected with the miR-650 mimic, while an opposite effect was observed in miR-650 inhibitor-transfected cells (Fig. 4B).

miR-650 regulates the release of allograft rejection-associated cytokines from HRGECs. ELISA was used to determine the levels of pro-inflammatory cytokines and chemokines. The results revealed that HRGECs transfected with the miR-650 mimic released a significantly higher amount of IFN- $\gamma$ and a significantly lower amount of IL-13 compared with HRGECs transfected with the miR-650 inhibitor and mock (Fig. 5A).

A chemotaxis assay was used to evaluate macrophage chemotaxis towards a conditioned medium from cells transfected with the miR-650 mimic, inhibitor or mock. The results revealed that the conditioned medium from miR-650 inhibitortransfected cells notably decreased macrophage migration compared with the miR-650 mock-transfected cells, whereas the medium from miR-650 mimic transfected-cells had a notably increased level of macrophage migration compared with the mock transfected cells (Fig. 5B).

$B C L 11 B$ as a target of miR-650. The computational prediction software packages miRBase, TargetScan, PicTar and miRanda were used to identify the potential binding sites for BCL11B mRNA on miR-650. It was revealed that the 3'-UTR of BCL11B mRNA possessed the miR-650 binding site (Fig. 6A) and that this binding site was conserved in mammals (data not shown). The effect of miR-650 on the translation of BCL11B mRNA into protein was evaluated using a luciferase reporter assay. The miR-650 mimic significantly decreased the luciferase activity of the reporter gene with a wild-type BCL11B 3'-UTR compared with the NC (Fig. 6B). However, the regulatory effect of miR-650 was suppressed when the predicted miR-650 binding site in BCL11B mRNA was mutated.

Transfection of BCL11B siRNA. The NC siRNA-transfected cells did not differ in any evaluation in all experimental groups (data not shown); therefore, the NC siRNA-transfected cells were used as a control for the BCL11B siRNA-transfected cells in all siRNA experiments. Knockdown of BCL11B 
A

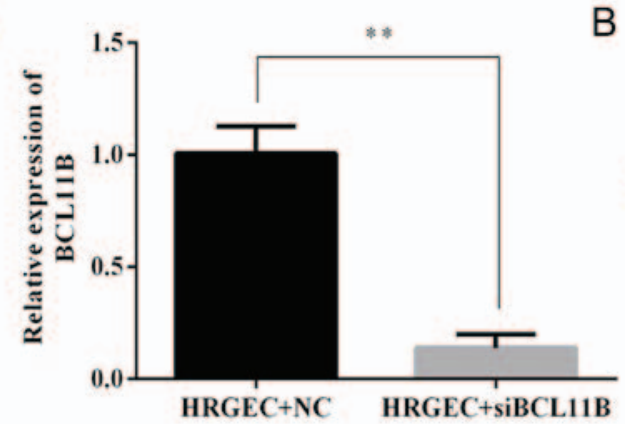

B

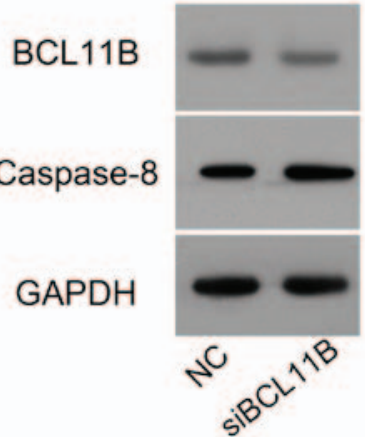

C
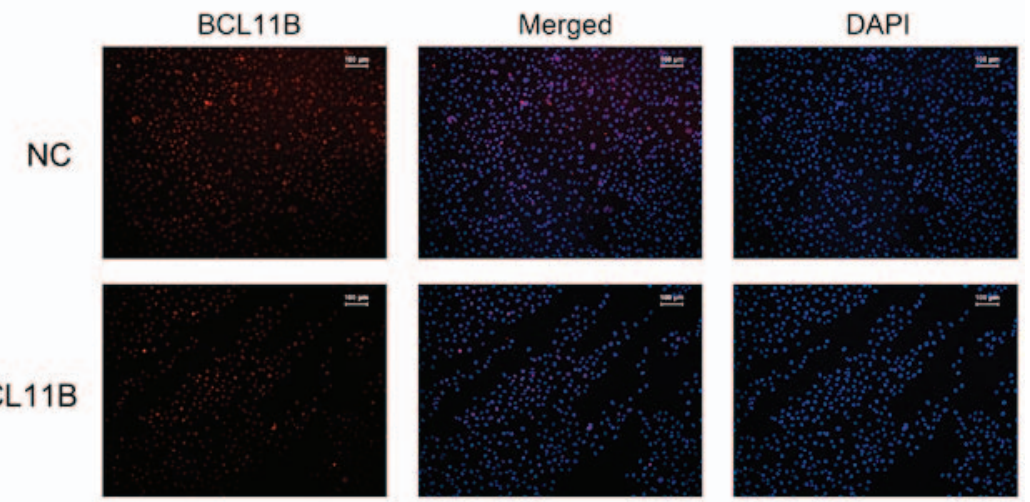

Figure 7. siRNA silencing of BCL11B. (A) The relative expression level of BCL11B in the NC group and the BCL11B-specific siRNA group was measured by ELISA. (B) Western blot analysis was used to measure the protein expression of caspase-8 and BCL11B. (C) The expression level of BCL11B was determined by immunofluorescence analysis. ${ }^{* *} \mathrm{P}<0.05$. siRNA, small interfering RNA; BCL11B, B-cell CLL/lymphoma 11B; NC, negative control; HRGEC, human renal glomerular endothelial cell; ELISA, enzyme-linked immunosorbent assay.

expression by BCL11B siRNA was evaluated by RT-qPCR, western blot analysis and immunofluorescence. The level of BCL11B in the BCL11B siRNA-transfected cells was significantly reduced compared with the NC cells (Fig. 7). A lower level of caspase- 8 protein expression was also observed in the BCL11B siRNA-transfected group (Fig. 7B).

Cell viability and apoptosis rates were measured by flow cytometry and a CCK8 assay. It was revealed that BCL11B siRNA transfection significantly increased the apoptotic rate of HRGECs in comparison with the NC (Fig. 8A and B). The survival of HRGECs was identified as being significantly reduced in cells transfected with BCL11B siRNA compared with the $\mathrm{NC}$ at $48 \mathrm{~h}$ after transfection (Fig. 8C).

To explore the combined effect of the miR-650 mimic and inhibition of BCL11B, BCL11B siRNA was transfected into HRGECs in combination with mock, inhibitor or mimic miR-650. Flow cytometry revealed that the apoptotic rate was significantly increased in cells transfected with BCL11B siRNA and the miR-650 mimic compared with the other combinations (Fig. 9A). Western blot analysis indicated that transfection of BCL11B siRNA combined with the miR-650 mimic further enhanced the expression of caspase- 8 in comparison with the other groups. (Fig. 9B)

\section{Discussion}

Acute renal rejection is a major cause of allograft dysfunction and the most common type of kidney transplant rejection (30). Acute renal rejection has a rapid onset and can occur just weeks after transplantation. The risk of developing acute renal rejection can be reduced by the use of prophylactic immunosuppressive drugs (31), which has dramatically decreased the incidence rate of acute renal rejection over the past three decades $(32,33)$. However, the optimization of immunosuppressive methods to prevent allograft rejection and minimize drug toxicity, infection and malignancy remains challenging. The early diagnosis of acute renal rejection is important for effective treatment with immunosuppressants and corticosteroids. Increasing evidence has demonstrated that miRNAs are differentially expressed in acute renal rejection and serve essential roles in its progression (34-36). Previous studies have reported that miRNAs may be used as a liquid biopsy tool, for applications including distinguishing squamous cell carcinoma in lung cancer biopsies (37), and predicting the pathological response (38) of patients with and without acute rejection $(39,40)$. This suggests that the abnormal expression of miRNAs is highly correlated with the progression of acute renal rejection where they serve an essential regulatory role. Therefore, the identification of miRNA markers may be critical for the early diagnosis of acute renal rejection.

Previous studies have revealed that specific miRNAs are favorable for the prediction of acute renal rejection, including miR-142-5q (41), miR-155 (42), miR-142-3q (43) and miR-223-3q (44). These miRNAs were identified to be upregulated in transplanted renal tissue and peripheral blood lymphocytes. In addition, urinary levels of specifics miRNAs have been considered as diagnostic markers for acute renal rejection; Lorenzen et al (45) identified a significantly decreased level of miR-210 in the urine samples from patients with acute renal rejection compared with those 

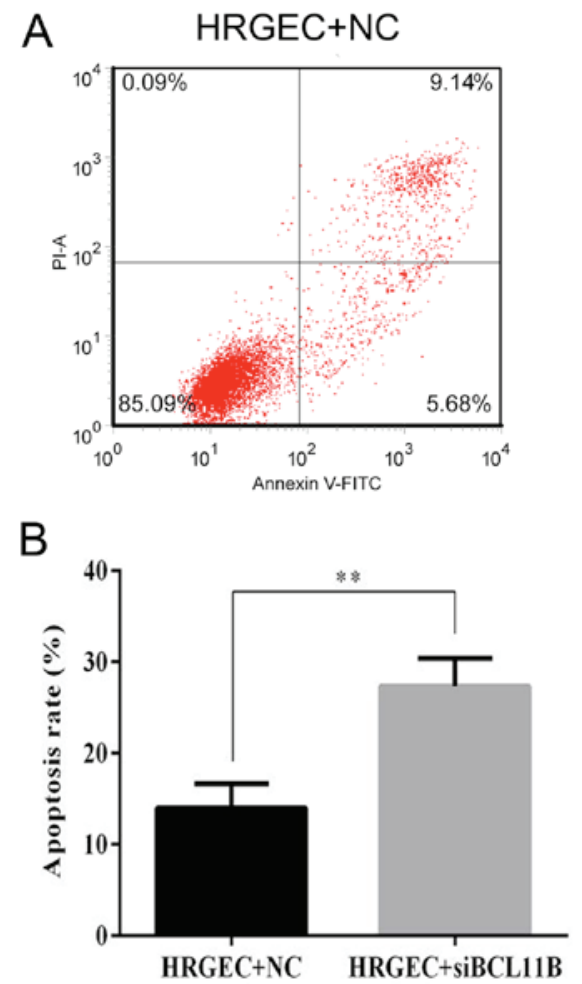
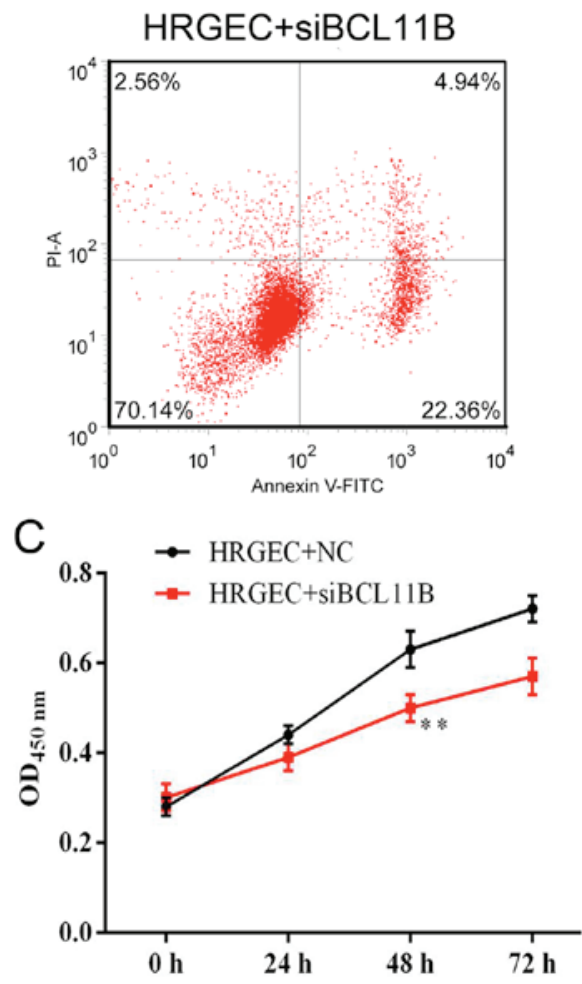

Figure 8. Silencing of BCL11B reduces HRGEC viability. (A) Flow cytometry was used to measure the apoptotic rate of the NC and siBCL11B groups, which was then (B) quantified. (C) A cell counting kit-8 assay was performed at 24,48 and $72 \mathrm{~h}$ after siRNA transfection. ${ }^{* *} \mathrm{P}<0.05 \mathrm{vs}$. the NC group. BCL11B, B-cell CLL/lymphoma 11B; HRGEC, human renal glomerular endothelial cell; siRNA, small interfering RNA; NC, negative control; FITC, fluorescein isothiocyanate; PI, propidium iodide; OD, optical density.
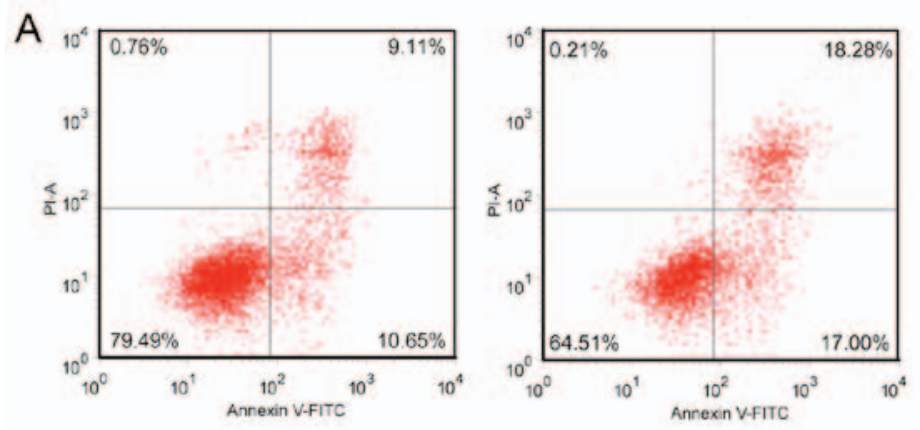

B
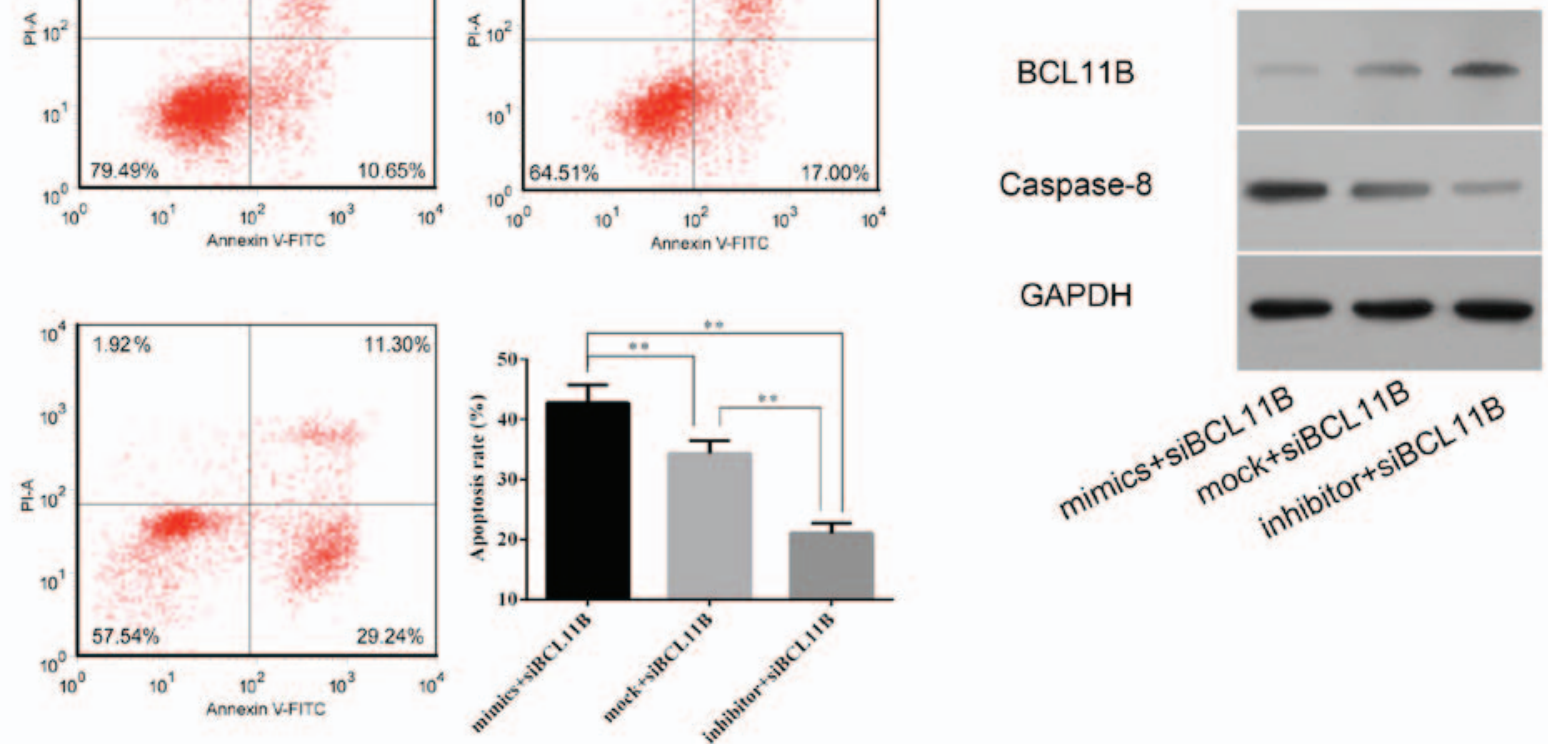

Figure 9. Effect of the co-transfection of the miR-650 mimic and BCL11B-specific siRNA. (A) The apoptotic rate was detected by flow cytometry. (B) Western blot analysis was performed to measure the protein expression of caspase-8 and BCL11B. ${ }^{* *} \mathrm{P}<0.05$. BCL11B, B-cell CLL/lymphoma 11B; miR, microRNA; siRNA, small interfering RNA; FITC, fluorescein isothiocyanate; PI, propidium iodide.

without rejection. In the present study, the expression and role of miR-650 in acute renal rejection was investigated. An increased expression of miR-650 was identified in patients with acute renal rejection compared with patients with normal allografts, which suggests that miR-650 may serve a functional role in the development of acute renal rejection. 
Furthermore, the in vitro model using HRGECs transfected with a miR-650 mimic revealed that the upregulation of miR-650 significantly suppressed cell proliferation and induced apoptosis. Transfection with the miR-650 mimic also significantly enhanced the release of inflammatory cytokines and chemokines, and promoted macrophage chemotaxis. These results suggest that miR-650 serves an essential regulatory role in acute renal rejection and may be considered as a potential diagnostic marker for acute renal rejection.

Previous studies have demonstrated that miR-650 contributes to the development of cancer by targeting tumor suppressor and apoptotic factors during cancer progression $(46,47)$. Huang et al (23) revealed that miR-650 is a prognostic factor in human lung adenocarcinoma and regulates the $\mathrm{B}$ cell lymphoma-2/Bax signaling pathway by targeting tumor suppressor inhibitor of growth protein 4. In the present study, it was revealed that the upregulation of miR-650 contributed to the apoptosis of HRGECs by targeting BCL11B. BCL11B, also known as CTIP2, is a transcriptional factor expressed in several different types of cancer, including lymphoma, melanoma and prostate cancer (48-50). BCL11B is implicated in multiple biological processes, including cell proliferation (51), apoptosis (52) and the immune response (53), as well as different pathological conditions, including cancer (54), inflammation (55), cardiac hypertrophy (56) and human immunodeficiency virus latency (57). Previous studies have demonstrated that BCL11B also contributes to T-cell development and T-cell identity $(53,58,59)$. Additionally, BCL11B serves a critical role in the production and release of cytokines, including IFN- $\gamma$, IL-5 and IL-13 (60-62). T-cells and cytokines are important modulators of acute renal injury (61). In the present study, it was revealed that BCL11B expression was negatively associated with the level of miR-650 and was significantly decreased in patients with acute renal rejection in comparison to patients with normal allografts. The potential binding sites for miR-650 on BCL11B mRNA were identified by computational prediction. The results of the present study suggest that miR-650 targets BCL11B mRNA, and that its upregulation reduces the expression of BCL11B, resulting in apoptosis, the release of cytokines and chemokines, and macrophage chemotaxis. The expression of caspase- 8 was also negatively associated with the level of BCL11B, indicating that apoptotic signaling was upregulated by the suppression of BCL11B in acute renal rejection. The effect of BCL11B demonstrated in the present study is different from its previously demonstrated effect as a tumor suppressor (63) and immune response inducer (64). The results of the present study also revealed mechanistic insights into the functioning of miR-650, as well as the novel regulatory role of BCL11B.

To the best of our knowledge, the present study is the first to demonstrate that the upregulation of miR- 650 contributes to the progression of acute renal rejection, which occurs via promoting apoptosis and immune responses through the targeting of BCL11B. In addition, the inhibition of miR-650 was identified to provide an efficient protective effect by reducing the expression of BCL11B, resulting in a lower level of apoptosis and immune responses, and increased cell migration. These results indicate that miR-650 is a potential novel diagnostic factor for acute renal rejection and may provide novel therapeutic strategies for its treatment.

\section{References}

1. Mas VR, Le TH and Maluf DG: Epigenetics in kidney transplantation: Current evidence, predictions, and future research directions. Transplantation 100: 23-38, 2016.

2. Li PK, Burdmann EA and Mehta RL; World Kidney Day Steering Committee 2013: Acute kidney injury: Global health alert. Transplantation 95: 653-657, 2013.

3. Van Sandwijk MS, Ten Berge IJ, Majoie CB, Caan MW, De Sonneville LM, Van Gool WA and Bemelman FJ: Cognitive changes in chronic kidney disease and after transplantation. Transplantation 100: 734-742, 2016.

4. Hakenberg O: Kidney transplantation. Urologe 54: 1355, 2015 (In German).

5. Verhave J, Boucher A, Dandavino R, Collette S, Senécal L, Hebert MJ, Girardin C and Cardinal H: The incidence, management, and evolution of rapamycin-related side effects in kidney transplant recipients. Clin Transplant 28: 616-622, 2014.

6. El Ters M, Grande JP, Keddis MT, Rodrigo E, Chopra B, Dean PG, Stegall MD and Cosio FG: Kidney allograft survival after acute rejection, the value of follow-up biopsies. Am J Transplant 13: 2334-2341, 2013.

7. Vlachopanos G and Georgalis A: On the value and pitfalls of follow-up biopsies after acute rejection. Am J Transplant 14: 237, 2014.

8. Goldberg RJ, Weng FL and Kandula P: Acute and chronic allograft dysfunction in kidney transplant recipients. Med Clin North Am 100: 487-503, 2016.

9. Becker LE, Morath C and Suesal C: Immune mechanisms of acute and chronic rejection. Clin Biochem 49: 320-323, 2016.

10. Hammond SM: An overview of microRNAs. Adv Drug Deliv Rev 87: 3-14, 2015.

11. Iwakawa HO and Tomari Y: The Functions of MicroRNAs: mRNA decay and translational repression. Trends Cell Biol 25: 651-665, 2015.

12. Ambros V: The functions of animal microRNAs. Nature 431: 350-355, 2004.

13. Small EM and Olson EN: Pervasive roles of microRNAs in cardiovascular biology. Nature 469: 336-342, 2011.

14. Fan PC, Chen CC, Chen YC, Chang YS and Chu PH: MicroRNAs in acute kidney injury. Hum Genomics 10: 29, 2016.

15. Lujambio A and Lowe SW: The microcosmos of cancer. Nature 482: 347-355, 2012.

16. Kim JK, Kim TS, Basu J and Jo EK: MicroRNA in innate immunity and autophagy during mycobacterial infection. Cell Microbiol 19: e12687, 2017.

17. Zawada AM, Zhang L, Emrich IE, Rogacev KS, Krezdorn N, Rotter B, Fliser D, Devaux Y, et al: MicroRNA profiling of human intermediate monocytes. Immunobiology 222: 587-596, 2017.

18. Oda H, Ikeguchi R, Yurie H, Kaizawa Y, Ohta S, Yamamoto K, Aoyama T and Matsuda S: Plasma microRNAs are potential biomarkers of acute rejection after hindlimb transplantation in rats. Transplantation Direct 2: e108, 2016.

19. Fujino M, Zhu P, Cai S, Nishio Y, Zhuang J and Li XK: MicroRNAs involved in acute rejection and tolerance in murine cardiac allografts. Exp Clin Transplant 14: 424-430, 2016.

20. Soltaninejad E, Nicknam MH, Nafar M, Ahmadpoor P, Pourrezagholi F, Sharbafi MH, Hosseinzadeh M, Foroughi F, Yekaninejad MS, Bahrami T, et al: Differential expression of microRNAs in renal transplant patients with acute T-cell mediated rejection. Transpl Immunol 33: 1-6, 2015.

21. Wilflingseder J, Reindl-Schwaighofer R, Sunzenauer J, Kainz A, Heinzel A, Mayer B and Oberbauer R: MicroRNAs in kidney transplantation. Nephrol Dial Transplant 30: 910-917, 2015.

22. Zhang X, Zhu W, Zhang J, Huo S, Zhou L, Gu Z and Zhang M: MicroRNA-650 targets ING4 to promote gastric cancer tumorigenicity. Biochem Biophys Res Commun 395: 275-280, 2010.

23. Huang JY, Cui SY, Chen YT, Song HZ, Huang GC, Feng B, Sun M, De W, Wang R and Chen LB: MicroRNA-650 was a prognostic factor in human lung adenocarcinoma and confers the docetaxel chemoresistance of lung adenocarcinoma cells via regulating Bcl-2/Bax expression. PLoS One 8: e72615, 2013.

24. Feng L, Xie Y, Zhang $\mathrm{H}$ and $\mathrm{Wu}$ Y: Down-regulation of NDRG2 gene expression in human colorectal cancer involves promoter methylation and microRNA-650. Biochem Biophys Res Commun 406: 534-538, 2011.

25. Zuo ZH, Yu YP, Ding Y, Liu S, Martin A, Tseng G and Luo JH: Oncogenic activity of miR-650 in prostate cancer is mediated by suppression of CSR1 expression. Am J Pathol 185: 1991-1999, 2015. 
26. Chien WW, Domenech C, Catallo R, Kaddar T, Magaud JP, Salles $\mathrm{G}$ and Ffrench M: Cyclin-dependent kinase 1 expression is inhibited by p16(INK4a) at the post-transcriptional level through the microRNA pathway. Oncogene 30: 1880-1891, 2011.

27. Mengel M, Sis B and Halloran PF: SWOT analysis of Banff: Strengths, weaknesses, opportunities and threats of the international Banff consensus process and classification system for renal allograft pathology. Am J Transplant 7: 2221-2226, 2007.

28. Livak KJ and Schmittgen TD: Analysis of relative gene expression data using real-time quantitative PCR and the 2(-Delta Delta C(T)) method. Methods 25: 402-408, 2001.

29. Farooqi AA, Qureshi MZ, Coskunpinar E, Naqvi SK, Yaylim I and Ismail M: MiR-421, miR-155 and miR-650: Emerging trends of regulation of cancer and apoptosis. Asian Pac J Cancer Prev 15: 1909-1912, 2014.

30. Aktaş A: Transplanted kidney function evaluation. Semin Nucl Med 44: 129-145, 2014.

31. Montero N, Pérez-Sáez MJ, Pascual J, Abramowicz D, Budde K, Dudley C, Hazzan M, Klinger M, Maggiore U, Oberbauer R, et al; DESCARTES Working Group; DESCARTES ERA-EDTA Board: Immunosuppression in the elderly renal allograft recipient: A systematic review. Transplant Rev (Orlando) 30 144-153, 2016.

32. O'Leary JG, Samaniego M, Barrio MC, Potena L, Zeevi A, Djamali A and Cozzi E: The influence of immunosuppressive agents on the risk of de novo donor-specific HLA antibody production in solid organ transplant recipients. Transplantation 100: 39-53, 2016

33. Watson CJ and Dark JH: Organ transplantation: Historical perspective and current practice. Br J Anaesth 108 (Suppl 1): i29-i42, 2012.

34. Xu Z, Yang W, Steward N, Sweet SC, Danziger-Isakov L, Heeger PS, Mohanakumar T: Role of circulating microRNAs in the immunopathogenesis of rejection following pediatric lung transplantation. Transplantation 101: 2461-2468, 2017.

35. Matz M, Lorkowski C, Fabritius K, Durek P, Wu K, Rudolph B, Neumayer HH, Mashreghi MF and Budde K: Free microRNA levels in plasma distinguish T-cell mediated rejection from stable graft function after kidney transplantation. Transpl Immunol 39: 52-59, 2016.

36. Schmuck RB, Reutzel-Selke A, Raschzok N, Morgul HM, Struecker B, Lippert S, de Carvalho Fischer C, Schmelzle M, Boas-Knoop S, Bahra M, et al: Bile: miRNA pattern and proteinbased biomarkers may predict acute cellular rejection after liver transplantation. Biomarkers 22: 19-27, 2017.

37. Patnaik S, Mallick R, Kannisto E, Sharma R, Bshara W, Yendamuri S and Dhillon SS: MiR-205 and MiR-375 microRNA assays to distinguish squamous cell carcinoma from adenocarcinoma in lung cancer biopsies. J Thorac Oncol 10: 446-453, 2015.

38. Wen J, Luo K, Liu H, Liu S, Lin G, Hu Y, Zhang X, Wang G, Chen Y, Chen Z, et al: MiRNA expression analysis of pretreatment biopsies predicts the pathological response of esophageal squamous cell carcinomas to neoadjuvant chemoradiotherapy. Ann Surg 263: 942-948, 2016.

39. Gharib SA, Edelman JD, Ge L and Chen P: Acute cellular rejection elicits distinct microRNA signatures in airway epithelium of lung transplant patients. Transplant Direct 1: e44, 2015.

40. Merhi B, Bayliss G and Gohh RY: Role for urinary biomarkers in diagnosis of acute rejection in the transplanted kidney. World J Transplant 5: 251-260,2015.

41. Iwasaki K, Yamamoto T, Inanaga Y, Hiramitsu T, Miwa Y, Murotani K, Narumi S, Watarai Y, Katayama A, Uchida K, et al: MiR-142-5p and miR-486-5p as biomarkers for early detection of chronic antibody-mediated rejection in kidney transplantation. Biomarkers 22: 45-54, 2017.

42. Anglicheau D, Sharma VK, Ding R, Hummel A, Snopkowski C, Dadhania D, Seshan SV and Suthanthiran M: MicroRNA expression profiles predictive of human renal allograft status. Proc Natl Acad Sci USA 106: 5330-5335, 2009.

43. Wei Q, Mi QS and Dong Z: The regulation and function of microRNAs in kidney diseases. IUBMB Life 65: 602-614, 2013.

44. Ulbing M, Kirsch AH, Leber B, Lemesch S, Münzker J, Schweighofer N, Hofer D, Trummer O, Rosenkranz AR, Müller H, et al: MicroRNAs 223-3p and 93-5p in patients with chronic kidney disease before and after renal transplantation. Bone 95: 115-123, 2017.

45. Lorenzen JM, Volkmann I, Fiedler J, Schmidt M, Scheffner I, Haller H, Gwinner W and Thum T: Urinary miR-210 as a mediator of acute T-cell mediated rejection in renal allograft recipients. Am J Transplant 11: 2221-2227, 2011
46. Yang IP, Tsai HL, Miao ZF, Huang CW, Kuo CH, Wu JY, Wang WM, Juo SH and Wang JY: Development of a deregulating microRNA panel for the detection of early relapse in postoperative colorectal cancer patients. J Transl Med 14: 108, 2016.

47. Zeng ZL, Li FJ, Gao F, Sun DS and Yao L: Upregulation of miR-650 is correlated with down-regulation of ING4 and progression of hepatocellular carcinoma. J Surg Oncol 107: 105-110, 2013.

48. Kominami R: Role of the transcription factor Bcll1b in development and lymphomagenesis. Proc Jpn Acad Ser B Phys Biol Sci 88: 72-87, 2012.

49. Uddin MN, Zhang Y, Harton JA, MacNamara KC and Avram D: TNF-alpha-dependent hematopoiesis following Bcl11b deletion in $\mathrm{T}$ cells restricts metastatic melanoma. J Immunol 192: 1946-1953, 2014

50. Mahapatra S, Klee EW, Young CY, Sun Z, Jimenez RE, Klee GG, Tindall DJ and Donkena KV: Global methylation profiling for risk prediction of prostate cancer. Clin Cancer Res 18: 2882-2895, 2012.

51. Li Z, Chen G, Yang Y, Guo W and Tian W: Bcl11b regulates enamel matrix protein expression and dental epithelial cell differentiation during rat tooth development. Mol Med Rep 15: 297-304, 2017.

52. Huang X, Chen S, Shen Q, Chen S, Yang L, Grabarczyk P, Przybylski GK, Schmidt CA and Li Y: Down regulation of BCL11B expression inhibits proliferation and induces apoptosis in malignant T cells by BCL11B-935-siRNA. Hematology 16: 236-242, 2011.

53. Hirose S, Touma M, Go R, Katsuragi Y, Sakuraba Y, Gondo Y, Abe M, Sakimura K, Mishima Y and Kominami R: Bcl11b prevents the intrathymic development of innate CD8 T cells in a cell intrinsic manner. Int Immunol 27: 205-215, 2015.

54. Huang X, Du X and Li Y: The role of BCL11B in hematological malignancy. Exp Hematol Oncol 1: 22, 2012

55. Wang Z, Zhang LJ, Guha G, Li S, Kyrylkova K, Kioussi C, Leid M, Ganguli-Indra G and Indra AK: Selective ablation of Ctip2/Bcll1b in epidermal keratinocytes triggers atopic dermatitis-like skin inflammatory responses in adult mice. PLoS One 7: e51262, 2012.

56. Cherrier T, Le Douce V, Eilebrecht S, Riclet R, Marban C, Dequiedt F, Goumon Y, Paillart JC, Mericskay M, Parlakian A, et al: CTIP2 is a negative regulator of P-TEFb. Proc Natl Acad Sci USA 110: 12655-12660, 2013.

57. Cismasiu VB, Paskaleva E, Suman Daya S, Canki M, Duus K and Avram D: BCL11B is a general transcriptional repressor of the HIV-1 long terminal repeat in T lymphocytes through recruitment of the NuRD complex. Virology 380: 173-181, 2008.

58. Takachi T, Takahashi M, Takahashi-Yoshita M, Higuchi M, Obata M, Mishima Y, Okuda S, Tanaka Y, Matsuoka M, Saitoh A, et al: Human T-cell leukemia virus type 1 Tax oncoprotein represses the expression of the BCL11B tumor suppressor in T-cells. Cancer Sci 106: 461-465, 2015.

59. Li L, Zhang JA, Dose M, Kueh HY, Mosadeghi R, Gounari F and Rothenberg EV: A far downstream enhancer for murine Bcl11b controls its T-cell specific expression. Blood 122: 902-911, 2013.

60. Liu P, Li P and Burke S: Critical roles of Bcl11b in T-cell development and maintenance of T-cell identity. Immunol Rev 238: 138-149, 2010.

61. Kinsey GR and Okusa MD: Expanding role of T cells in acute kidney injury. Curr Opin Nephrol Hypertens 23: 9-16, 2014.

62. Yu Y, Wang C, Clare S, Wang J, Lee SC, Brandt C, Burke S $\mathrm{Lu} \mathrm{L}, \mathrm{He} \mathrm{D}$, Jenkins NA, et al: The transcription factor Bcl11b is specifically expressed in group 2 innate lymphoid cells and is essential for their development. J Exp Med 212: 865-874, 2015.

63. Gutierrez A, Kentsis A, Sanda T, Holmfeldt L, Chen SC, Zhang J, Protopopov A, Chin L, Dahlberg SE, Neuberg DS, et al: The BCL11B tumor suppressor is mutated across the major molecular subtypes of T-cell acute lymphoblastic leukemia. Blood 118: 4169-4173, 2011

64. Zhong $\mathrm{C}$ and Zhu J: Bcl11b drives the birth of ILC2 innate lymphocytes. J Exp Med 212: 828, 2015.

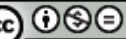

This work is licensed under a Creative Common Attribution-NonCommercial-NoDerivatives 4.0 International (CC BY-NC-ND 4.0) License. 